ESTUdios INTERNACIONALES I 58 (2007) - ISSN 07I6-0240 • 29-57

Instituto de Estudios Internacionales - Universidad de Chile

\title{
La ampliación de la Unión Europea
}

The expansion of the European Union

\author{
Jaime Lagos Erazo*
}

\section{Resumen}

En sus 50 años de existencia, la Unión Europea ha convertido el tema de la ampliación en uno de sus mayores éxitos políticos. El llamado «Big Bang de Copenhague» (2002), que aumentó la membresía de la Unión a 25 miembros, seguida en 2007 por la incorporación de otros dos, ha tenido un enorme significado político e histórico ya que puso término a la artificial división de Europa. La construcción de la actual «Gran Europa» ha sido fruto de un largo proceso de ampliaciones sucesivas, que más de un vez han provocado diferencias entre las corrientes que cohabitan al interior de la Unión Europea. Unas prefieren la «consolidación» y otras abogan por la «expansión». En definitiva, ambos procesos se desarrollaron de manera convergente dando lugar a importantes cambios institucionales y financieros en la arquitectura de la Unión. Los ajustes institucionales aún están en pleno proceso de desarrollo con el nuevo Tratado de Lisboa, cuyas bases se aprobaron recientemente. La ampliación ha provocado serios desafíos a la Unión Europea, tales como el de superar el «euro escepticismo» que prevalece en la ciudadanía. En este contexto, el mayor de ellos es la incorporación de Turquía.

Palabras Clave: reunificación europea, cambios institucionales, euro fatiga, capacidad de absorción, adhesión de Turquía.

Profesor Universidad Finís Terrae (jlagose@vtr.cl).

Recibido el 6 de octubre de 2007; aceptado el 14 de noviembre de 2007. 


\section{Abstract}

In its 50 years of existence, the EU has managed to transform «enlargement» in one of its most important political achievements. The so called «Big Bang» of Copenhagen, (2002) increased its membership to 25 followed in 2007 by another two former communist States, event that has had a powerful historical and political impact, putting an end to the artificial division of Europe. The building up of the "Great Europe» has been a long process of successive enlargements which more than once has led to differences in the forces coexisting inside the European Union: those who prefer "consolidation" and those that opt for «expansion». However, both processes developed side by side, resulting in significant changes in the institutional and financial architecture of the Union. Institutional adjustments are still being developed in the recently adopted Lisbon Treaty. Enlargement has brought about serious challenges for the European Union, such as how to cope with the «Euro scepticism» of its citizens. In this context, ones of the most difficult one is the admission of Turkey.

KEW wORDS: unification of Europe, institutional changes, euro scepticism, absorption capacity, admission of Turkey. 


\section{A. El PROCESO DE AMPLIACIÓN}

\section{El «Big Bang de Copenhague»}

En diciembre del 2002, en circunstancias que Dinamarca ejercía la presidencia rotativa de la Unión Europea, se formalizaba en el Consejo Europeo de Copenhague el llamado «Big Bang», la quinta y más ambiciosa ampliación de esta entidad: su expansión de 15 a 25 miembros, que se concretó el 1 de mayo de 2004. Entonces, 10 nuevos países se incorporaron a la Unión como miembros plenos.

En esa fecha sus líderes fueron recibidos en una solemne ceremonia en el Castillo de Dublín por los 15 Jefes de Estado y de Gobierno de sus restantes socios europeos, algunos fundadores y otros que se sumaron más tarde: Alemania, Francia, Italia, Bélgica, Holanda, Luxemburgo, Reino Unido, Irlanda, Dinamarca, Grecia, España, Portugal, Suecia, Finlandia y Austria.

Los miembros que fueron aceptados de inmediato eran seis países ex comunistas de Europa central y oriental (Polonia, la República Checa, Eslovaquia, Hungría, Eslovenia), tres países bálticos (Estonia, Letonia, y Lituania) y dos islas mediterráneas (Malta y Chipre). Las accesiones de Bulgaria y Rumania se postergaron hasta el 1 de enero de 2007.

Paralelamente, en las respectivas capitales de esos ocho Estados comunistas tenían lugar ceremonias conmemorativas del evento, en las cuales sus ciudadanos demostraron regocijo por haberse finalmente reintegrado a la gran familia europea después de más de cuarenta años de dominio soviético y a los quince años de haber recuperado su independencia.

Más tarde, el 1 de mayo de 2004, en la sede del Parlamento (Sejm) de Vilnius, capital de Lituania y en la calles de su bella ciudad vieja, pude apreciar el hondo significado que este acontecimiento tenía para esos pueblos por años mantenidos al margen de las corrientes de democracia y progreso que imperaban en el resto de Europa. La "vieja» y la «nueva» Europa se entrelazaban finalmente en un común proyecto de paz, estabilidad y prosperidad.

Con este gigantesco paso la Unión Europea borraba los últimos vestigios de las barreras que impuso la Guerra Fría, siendo el corolario indispensable de la caída del Muro de Berlín en noviembre de 1989, que fue el acontecimiento que precipitó esta reintegración. El sueño de la unificación europea se convertía en realidad relegando al pasado la artificial división de ese Continente que ahora pasaba a caracterizarse como la «Gran Europa». Como lo expresó el Primer Ministro danés Fogh Rasmussen, anfitrión de la cita de Copenhague, la nueva Europa que nacía cerraba «uno de los más sanguinarios y más oscuros capítulos en la historia europea».

Por su simbolismo y significado práctico, dicha ampliación constituyó uno de los momentos más estelares del rico historial del proyecto europeo en sus 50 años de existencia. 
La Unión Europea, ampliada al 1 de enero del 2007 a 27 miembros pasó a contar con 492 millones de habitantes (solo superada en población por China e India), que hablan 27 idiomas (23 de ellos idiomas oficiales), convirtiéndose en el más poderoso bloque económico y comercial mundial, en el mayor mercado único del planeta y en un actor de más gravitante peso en el escenario internacional.

Geográficamente, con una superficie de más de 4 millones de $\mathrm{kms}^{2}$, las fronteras de la UE se extienden ahora en el continente europeo desde el Océano Atlántico por el oeste hasta el Mar Negro por el oriente y desde el Báltico por el norte hasta el Mar Mediterráneo por el sur.

El hecho de haber sido testigo presencial de estos acontecimientos me ha llevado a escribir una reseña de los principales hitos de la ampliación de la Unión Europea que se encuentra en el corazón mismo de todo el proceso de la construcción europea, que desde sus orígenes ha tenido amplias ramificaciones en la arquitectura institucional y financiera de la Unión. Pero, como se verá más adelante, no se trata solo de un tema de éxitos puesto que ha estado impregnado de retrocesos y de momentos traumáticos. Asimismo, sigue provocando serios desafíos a la Unión Europea, sobre todo por el hecho de que otros Estados siguen golpeando sus puertas para adherirse a ella, entre los cuales Turquía representa potencialmente la situación más riesgosa y difícil de resolver. La adaptación de esos nuevos Estados a las exigencias de la membresía no ha sido fácil y muchos ciudadanos europeos aún se preguntan si es posible absorber esa ampliación, sobre todo la última.

El proceso también ha debido superar las corrientes centrípetas y centrífugas que cohabitan al interior de la Unión Europea. Las primeras prefiriendo la «profundización», o sea la consolidación, antes que la "ampliación», querella que resurgió con mayor fuerza tras la caída del imperio soviético, ya que se temía que la expansión resultante de ese acontecimiento socavara las bases de lo que se estaba construyendo con tanto esfuerzo.

En estos últimos años, todo ello ha generado entre los ciudadanos europeos lo que se ha caracterizado como la «euro fatiga» o el «euro escepticismo», difícil prueba que la Unión Europea en su conjunto ha debido enfrentar y que no ha estado exenta de polémicas y de aprensiones.

\section{Sucesivas ampliaciones}

Hay que remontarse a Jean Monnet, uno de los fundadores de la Unión Europea, para comprender que la expansión de la Unión Europea corresponde a una visión que se tenía desde los comienzos del proyecto europeo, en los años cincuenta. Entonces, con su reconocida clarividencia, el político francés anticipaba que en un mundo globalizado el «tamaño» sería determinante. Según sus palabras «nuestros 
países son muy pequeños en el mundo actual... medidos en función de América y de Rusia en el día de hoy y de China y de India mañana» ${ }^{1}$.

Por lo tanto, la expansión y la unificación de Europa, actuando con una sola voz, ha sido desde siempre una necesidad política manifestada por los líderes europeos. Más concretamente, «la ampliación», aunque ahora con límites más circunscritos y no obstante sus detractores, siempre ha estado en el centro de los objetivos de la Unión Europea y como lo dijo la Comisión Europea en 2005 ha sido «uno de sus instrumentos políticos más poderosos».

No obstante esta vocación integracionista, en los orígenes históricos de la CECA y de la Comunidad Económica Europea (CEE) y de la EURATOM, que nacieron respectivamente del Tratado de París (1951) y de los Tratados de Roma (1957), aparecieron los primeros gérmenes de disensión respecto de cuáles serían los nuevos Estados que se unirían al núcleo de los seis miembros fundadores (Francia, Alemania, Italia, Holanda, Bélgica y Luxemburgo) no obstante que esta original empresa creada entonces permanecía abierta a todos los Estados europeos $^{2}$. Estas diferencias fueron los

1 «Europe is losing faith in its most succesful policicy, Financial Times», $12 \mathrm{de}$ diciembre 2006.

2 En efecto, el artículo 237 del Tratado de Roma estableció que «cualquier Estado europeo puede solicitar ser miembro de la Comunidad». Esta invitación tan amplia estaba sin embargo calificada en el preámbulo de este acuerdo que se refería a la voluntad de los Estados fundadores de primeros signos de que algunos Estados miembros preferían «la profundización» antes que la «ampliación».

\section{a) La primera ampliación (Reino Unido, Irlanda y Dinamarca)}

Precisamente en la primera ampliación de las Comunidades Europeas ${ }^{3}$, se registraría el primer tropiezo en este accidentado camino y afectó al Reino Unido, país que inicialmente por su propia voluntad quedó fuera de ella y prefirió crear en 1960 la Asociación Europea de Libre Comercio (más conocida por EFTA, por su sigla en inglés) con otros siete Estados de Europa occidental (Austria, Dinamarca, Islandia, Noruega, Portugal, Suecia y Suiza).

Pero al poco tiempo el Reino Unido se percató de los logros económicos que estaba alcanzando el conjunto

fortalecer la paz y la libertad y llamaba a «los otros pueblos de Europa que comparten este ideal de unirse a estos esfuerzos», de modo que siempre se consideró que solo aquellos gobiernos que fuesen democráticos podían incorporarse al proyecto europeo.

3 En el desarrollo de este trabajo utilizaremos la expresión «Comunidades Europeas» o «Comunidad» que abarca tanto a la CECA (Comunidad Europea del Carbón y del Acero), como a la CEE (Mercado Común) y el la EURATOM (Comunidad Europea de Energía Atómica), las que fueron refundidas en 1965 pero manteniendo las mismas instituciones y membresía, aunque con personalidad jurídica distinta. La CEE se convirtió en Comunidad Europea (CE) por el Tratado de Maastricht. 
comunitario de los Seis, que con sus 170 millones de habitantes parecía un espacio mucho más favorable para sus intereses comerciales que la EFTA, con sus 90 millones de ciudadanos.

Por ello, en julio de 1961, solicitó formalmente su incorporación a las Comunidades, paso que sería seguido poco después por Irlanda, Dinamarca y Noruega. Su adhesión fue recibida con beneplácito por cinco de los seis miembros fundadores, pero trascendió que el presidente Charles de Gaulle se opuso al ingreso británico e incluso, según algunas fuentes, era hostil a la incorporación de una "nación anglosajona» por estar más inclinada hacia Estados Unidos que a Europa. El llamado "anclaje atlántico» provocaba suspicacias en los franceses, cuando para muchos otros precisamente este factor debería haberlos conducido a atraer más hacia Europa a uno de sus Estados más poderosos.

El veto francés de 1963 se renovó en 1967, acrecentando las tensiones que se habían producido con el primer rechazo, dejando en Gran Bretaña un profundo resentimiento hacia los franceses.

Fue necesario esperar que el General de Gaulle desapareciera de la escena política en 1969 para que el ingreso del Reino Unido, en su tercera tentativa, fuese examinado bajo otras perspectivas (Conferencia de La Haya). Se entablaron entonces negociaciones de adhesión con los cuatros países antes mencionados, que materializaron en el Tratado y las Actas de Adhesión de
1972, y entraron en vigor el 1 de enero de 1973.

De este modo, las Comunidades Europeas pasaban a contar con nueve miembros, ya que entretanto Noruega, por un referéndum de sus ciudadanos resolvió permanecer al margen. En cambio, en Dinamarca e Irlanda similares consultas populares dieron resultados favorables.

Con esta primera ampliación de seis a nueve miembros, la CEE pasaba de 191 millones a 255 millones de habitantes. Pero a pesar de este reforzamiento, la cohesión que había existido entre los Seis se había diluido ya que la hostilidad de amplios sectores de la opinión pública del Reino Unido y Dinamarca hacia la Comunidad dificultaba su desarrollo y la aplicación de las necesarias medidas de compromiso para poder avanzar en la integración europea.

Entretanto, en el horizonte ya se visualizaba la incorporación de tres nuevos miembros: Grecia, Portugal y España, que habían presentado sus candidaturas, el primero en 1975, y los otros dos Estados de la Península Ibéricas en 1977. Mientras languidecían bajo la tutela de regímenes dictatoriales estos países habían quedado excluidos de toda opción de insertarse en el ambicioso proyecto europeo que se estaba construyendo.

\section{b) La segunda ampliación (Grecia)}

Recuperada la democracia en 1974, este país mediterráneo, que ya estaba 
asociado con las Comunidades desde 1961, no dejó pasar mucho tiempo antes de que presentara su solicitud de adhesión en 1975 como miembro pleno. Así, Grecia se convirtió en el décimo miembro el 1 de enero de 1981.

Con esta ampliación, la Europa de los Nueve se extendía hacia el sur y hacia un país con menor nivel de desarrollo que sus restantes socios.

Las negociaciones con Grecia resultaron relativamente fáciles, ya que el gobierno helénico no puso demasiadas exigencias para su ingreso.

Mucho más difícil en cambio fue la adhesión que ya se negociaba con España y Portugal.

c) La tercera ampliación (España y Portugal)

Había llegado, como sostienen algunos autores españoles ${ }^{4}$, la «hora de la Península Ibérica» pero la adhesión de esos Estados fue más extensa y compleja que todas las anteriores. Las negociaciones respectivas, que se iniciaron en 1979 , se arrastraron por largos siete años.

Con pocos meses de diferencia, ese año Portugal y España solicitaron la apertura de negociaciones para la adhesión a las Comunidades Europeas en 1977. Vale decir, al poco tiempo de la revolución portuguesa de 1974 y de la

4 Bernard, Maximiliano, Sergio Salinas y Carmen Tirado (2003), Instituciones y Derecho de la Unión Europea, Zaragoza, Realizaciones, Informes y Ediciones Europa, pp. 41-42. muerte de Franco en 1975, una vez que habían recuperado la democracia. Por ello, la consolidación de la democracia y una reorientación hacia Europa eran los factores determinantes que los inducían a buscar este acercamiento.

Estas negociaciones fueron más duras porque ambos países formularon mayores exigencias, pero al mismo tiempo porque hubo mayor oposición al interior de la Comunidad, y sobre todo de Francia, a su incorporación. Fundamentalmente, los sectores agrícolas del sur de Francia e Italia y de Grecia miraban con preocupación sobre todo la competencia de la agricultura española en productos con excedentes como los vinos, las semillas, las frutas y las hortalizas. Se temía además un fuerte éxodo migratorio de esos dos países hacia el resto de la Comunidad.

Finalmente, las negociaciones culminaron con la firma en Madrid y Lisboa de los Tratados de Adhesión el día 12 de junio de 1985. Estos Tratados entraron en vigor el 1 de enero de 1986.

La incorporación de España, Portugal y Grecia en la Comunidad dejaría una importante impronta en el esfuerzo de ampliación posterior, ya que todas las aprensiones que provocó su admisión resultaron infundadas (un excesivo flujo de corrientes migratorias, desnivel de desarrollo con el resto de los socios europeos, entre otras). 
d) La cuarta ampliación (Austria, Finlandia y Suecia)

Esta sería la primera ampliación luego de la suscripción, el 7 de febrero de 1992, del Tratado de Maastricht, esto es, del Tratado de la Unión Europea. Se trataba, por lo tanto, de la primera expansión de la Unión, que a contar del 1 de enero de 1995 pasaba a convertirse en una entidad con 15 miembros y 370 millones de habitantes.

Las negociaciones de adhesión con Austria, Finlandia, Suecia y Noruega se iniciaron a comienzos de 1993 y concluyeron exitosamente en marzo de 1994. Referendos de aprobación tuvieron lugar al poco tiempo en Austria, Finlandia y Suecia, con resultados favorables. En cambio, por segunda vez, los ciudadanos noruegos se opusieron a incorporarse a la Unión Europea.

La adhesión de estos Estados se vio facilitada por el hecho de que formaban parte del Espacio Económico Europeo (EEA) que la CEE había convenido con los miembros de la EFTA. Pero dichos Estados, junto con Suiza, decidieron cambiar de bando, ya que la Unión Europea les reportaba mayores ventajas económicas. Inicialmente Suiza también se inclinó por esa opción, pero el rechazo de su ciudadanía en el EEA obligó a sus autoridades a congelar su demanda de adhesión, situación que se mantiene hasta hoy. Otros dos Estados europeos miembros de la EFTA, Liechtenstein e Islandia, el primero por su exigua población y el segundo para defender su industria pesquera, no aspiraron a ser miembros de la Unión Europea.

Las negociaciones con los cuatros países nombrados no plantearon mayores dificultades. Los cuatro tenían altos ingresos per cápita y en definitiva serían contribuyentes netos a los fondos de la Unión.

Además, con el término de la Guerra Fría se habían disipado los problemas que se anticipaban debido a la política de neutralidad de Austria, Finlandia y Suecia.

Esta nueva ampliación obligó a introducir cambios en las instituciones (tres nuevos asientos en la Comisión Europea, aumento del número de diputados en el Parlamento Europeo y ponderación de los votos para bloquear las decisiones).

En los años noventa también se produciría un importante debate con motivo de la reunificación de Alemania y la desaparición de la ex República Democrática Alemana (RDA). Finalmente, se resolvió que no era necesaria su adhesión a la Unión Europea y que su integración se haría a través de los Estados federales (Länder) de la RDA que se incorporaron al territorio alemán, fijándose un periodo de transición debido a las disparidades en materia de desarrollo económico.
e) La quinta ampliación
(12 nuevos Estados)

Como ya se señaló, el 1 de mayo de 2004 la Unión Europea experimentó 
mayor y más simbólica ampliación en la historia del proceso de integración europea. La incorporación primero de ocho Estados de Europa central y oriental (PECO) y bálticos, sumados a Chipre y Malta, hicieron crecer la Unión un tercio geográficamente y un quinto en población (de 379 a 455 millones de habitantes). La posterior adhesión de Rumania (22 millones) y de Bulgaria ( 8 millones) aumentó la familia europea a 492 millones de ciudadanos.

Entre los antiguos y nuevos miembros existían grandes desniveles de desarrollo, lo que constituía un serio obstáculo inicial, razón por la cual su incorporación fue fruto de un avance gradual $^{5}$. Para llegar a ella fue necesario un largo proceso que se prolongó prácticamente por quince años.

Después de la Cumbre de Copenhague (2002), se contemplaron dos años adicionales para que materializara formalmente la adhesión de los diez nuevos miembros, tiempo necesario para que se realizaran los trámites internos de ratificación del Tratado de Adhesión, que contenía más de seis mil páginas, el que fue suscrito en Atenas el 16 de abril de 2003. En la casi totalidad de los nuevos miembros, con la excepción de Chipre, dicha ratificación se efectuó mediante referendos, que recibieron amplio apoyo. Similar aprobación fue

$5 \quad$ El producto interno bruto de los nuevos miembros se situaba en promedio en un $50 \%$ de la media de la Unión Europea, siendo el más bajo el de Letonia $(35 \%)$ y el más alto el de Eslovenia (74\%). Fuentes: Comisión Europea, Eurostat. necesaria de parte de los antiguos 15 miembros y de los órganos de la Unión Europea.

Cabe recordar que la Cumbre de Copenhague no estuvo exenta de dramatismo. Las negociaciones entre los líderes europeos se extendieron por largas horas más allá de lo contemplado, ante los intentos de los nuevos miembros, encabezados por Polonia, que pretendían obtener mejores ventajas financieras que las acordadas por la UE para los países candidatos (40,9 mil millones de euros para el periodo 2004-2006, básicamente para el desarrollo agrícola y para los fondos regionales). Para los países candidatos esta cifra era bruta, ya que una vez que pagaran sus contribuciones a la Unión Europea se reducía a 12 mil millones de euros.

Finalmente, Alemania, el mayor contribuyente de la Unión Europea, consciente de que esta ampliación carecería de significado, en particular si se excluía a Polonia, se manifestó en la hora undécima dispuesta a efectuar una contribución adicional a todos los países candidatos (300 millones de euros y para Polonia mil millones de euros de créditos en efectivo para financiar su presupuesto en el mismo periodo señalado $)^{6}$. En ese momento quedó en evidencia que en el futuro Polonia sería un miembro difícil de satisfacer, ya que por el tamaño de su población, su sacrificado pasado histórico y presiones

6 Financial Times, 14/15 de diciembre de 2002. 
internas aparecía como un "porfiado» socio en la defensa de sus intereses nacionales. Ello se manifestaría sobre todo durante la aprobación del Tratado de Niza (2001), que introdujo importantes modificaciones institucionales para acoger la expansión de la Unión Europea.

En cuanto a la adhesión de Bulgaria y Rumania, fue retrasada hasta el 1 de enero del 2007 debido a varios contratiempos. En estos casos, la incorporación se pospuso ya que ninguno de los dos países había concluido las negociaciones de adhesión con la Unión Europea cuando tuvo lugar la Cumbre de Copenhague y evidenciaban rezagos importantes, sobre todo en materia de administración de justicia (crimen organizado) y lucha contra la corrupción. Para que cumplieran estas exigencias, amén de otras, ambos países fueron sometidos a una evaluación sin precedentes y se les otorgaron fuertes ayudas financieras. Las condiciones que se les han impuesto se consideran un ejemplo para futuras negociaciones de pre-adhesión 7 . Todo ello para responder a las severas críticas que la admisión de estos dos países que tenían fuertes retrasos institucionales, políticos y económicos ${ }^{8}$ provocó a nivel europeo.

7 «Enlargement Strategy and Main Challenges 2006-2007», Comunicación de la Comisión Europea al Parlamento y a la Comisión «http://ec.europa.eu/enlargement/pdf/key_documents/2006/nov.com649-strategy».

8 Bulgaria y Rumania son mucho más pobres que el resto de la Unión Europea, con un Producto Interno Bruto (PIB) que al-
El eventual éxodo de su mano obra obligó también a adoptar restricciones a la libre circulación en la mayoría de los 15 Estados anteriores miembros de la Unión Europea, con las excepciones de Finlandia y Suecia. Los diez nuevos Estados miembros, entre ellos el mayor (Polonia) aseguraron que no impondrían tales restricciones.

f) Cronología de la última ampliación

Según sostiene Jean-Louis Quermonne ${ }^{9}$ «la querella de la profundización y la expansión resurgió a fines de los años ochenta en razón de la caída del Muro de Berlín y la implosión del imperio soviético. De nuevo Gran Bretaña, apoyada por Dinamarca, sostuvo su tesis en favor de una expansión precipitada; pero bajo la influencia del par franco-alemán, se decidió que salvo en circunstancias excepcionales, ninguna solicitud de adhesión sería examinada, antes del comienzo de 1993».

Con ello, el autor francés se refería al temor de que después de la «caída

canza al 33\% del promedio europeo, comparado con el 50\% de Polonia.

Como puntualiza un artículo de la revista Economist titulado "The new kids in the block», de 5 de enero de 2007, el PIB per cápita de Bulgaria en 2005 era solo de dólares 3.480, y el de Rumania dólares 4.490, en comparación con los dólares 9.240, de los nuevamente admitidos y dólares 29.330 del resto del promedio europeo».

9 «El sistema político de la Unión Europea», op. cit, p. 168. 
del muro comunista» se iniciara una «expansión incontrolada» que diluyera económicamente a la Comunidad Europea en una gran zona de libre comercio y políticamente se convirtiera en una vaga confederación de Estados. Por ello se dio preferencia a la profundización que condujo al Tratado de Maastricht, pero a la vez sin eludir la expansión que ya estaba en marcha.

Caído el Muro de Berlín, los nuevos Estados que emergían del comunismo consideraron que su destino se encontraba ligado a su participación en las instituciones atlánticas y europeas (OTAN y UE, principalmente). La Unión Europea no solo aparecía como una fuente importante de asistencia económica sino además como un instrumento para garantizar su desarrollo democrático.

Por esa época, el líder polaco Lech Walesa instaba a construir «un hogar común europeo». Como anota el diario Financial Times ${ }^{10}$ "los líderes europeos reaccionaron con calurosas palabras de bienvenida (a este interés) pero en la práctica arrastraron sus pies» principalmente porque a la sazón Alemania estaba preocupada de incorporar a Alemania oriental. Además, dieron prioridad a la construcción de un Espacio Económico Europeo (EEE) y a la incorporación de Austria, Suecia, Finlandia y Noruega, que se gestaba al mismo tiempo.

Sin perjuicio de la postergación hasta 1993 de las decisiones sobre la adhesión de los PECO y de Chipre y

10 «European Union Enlargement», 10 diciembre 2002.
Malta, la Unión Europea adoptaba diversos pasos para integrar a estos países, proceso que se inició con la firma en 1991 de los primeros acuerdos de asociación con Hungría, Polonia y la ex Checoslovaquia, extendiéndose después hasta 1994 a los restantes PECO. Los acuerdos daban a la mayoría de las exportaciones procedentes de Europa central y oriental un acceso preferente a los mercados de la Unión Europea, además de asistencia financiera y de cooperación. Estos instrumentos, asimismo, reconocían explícitamente que los países involucrados eventualmente serían elegibles como miembros plenos. Con Chipre y Malta existían esos acuerdos desde los años setenta.

Los convenios de asociación mencionados se acompañaron del programa de ayuda PHARE, adoptado en 1989, y de dos programas complementarios de asistencia posteriores: el IPSA, de apoyo al desarrollo de la infraestructura y el SAPARD, para la modernización de la agricultura.

En fin, en la Cumbre de Copenhague de 1993 el proceso de ampliación se encauzaba por un derrotero más seguro, si bien las adhesiones tardarían todavía varios años en formalizarse.

En esa reunión Cumbre de Jefes de Estado y de Gobierno se estableció expresamente que los países asociados de Europa central y oriental que lo desearan, podrian devenir miembros de la Unión Europea. La adhesión tendría lugar apenas el país miembro asociado estuviera en condiciones de cumplir con las obligaciones pertinentes, cumplien- 
do con las condiciones económicas y políticas requeridas.

Estas últimas fueron los llamados «criterios de Copenhague» que establecían los siguientes requisitos de membresía:

- Políticos: instituciones estables que garanticen la democracia, el Estado de derecho, los derechos humanos y el respeto de las minorías;

- Económicos: una economía de mercado que pueda hacer frente a las presiones competitivas y a las fuerzas de mercado dentro de la Unión;

- Técnicos y jurídicos: capacidad para asumir las obligaciones que impone la adhesión (acervo comunitario ${ }^{11}$ ), incluido el apoyo a los objetivos de la Unión; y una administración pública capaz de aplicar y gestionar la legislación comunitaria.

11 El llamado «acervo comunitario», comúnmente conocido por su nombre en francés l'acquis communautaire, básicamente significa «la Unión Europea tal como es» es decir, los derechos y obligaciones compartidos por los países de la Unión Europea. Incluye todos los tratados y leyes de la UE, declaraciones y resoluciones, acuerdos internacionales y sentencias dictadas por el tribunal de Justicia. También incluye las medidas que los gobiernos de la UE toman conjuntamente en el campo de la justicia e interior y en la política exterior y de seguridad común. Los países candidatos tienen que aceptar el acervo antes de poder formar parte de la Unión Europea y trasladar a su legislación nacional las leyes de la Unión Europea. Esta descripción se encuentra en el glosario contenido en la obra de José Ignacio Martínez Estay, Introducción al Derecho y a las Instituciones de la Unión Europea, Santiago, Editorial Jurídica de Chile, 2007.
El llamado itinerario de "Copenhague (1993) a Copenhague (2002)» tendría todavía frente a sí un largo y complejo recorrido de preparación para que se concretara la ansiada ampliación, cuyo claro objetivo ya era la «reunificación de Europa». Para ello se pusieron en marcha dos procesos convergentes: un proceso de preadhesión cuya estrategia fue definida en el Consejo Europeo de Essen de $1994{ }^{12}$ y un proceso de ampliación propiamente tal que conduce, según el ritmo a definir, a la apertura de negociaciones con los países candidatos.

En la primera fase de este proceso cobró especial importancia la presentación en 1997 de un informe de más de mil páginas por la Comisión Europea (informe Santer) al Parlamento Europeo, la denominada "Agenda 2000», que analiza los posibles impactos de la ampliación y el futuro marco financiero $^{13}$.

Con posterioridad, cabe mencionar como hito importante en el proceso de preadhesión el Consejo Europeo de Ber-

12 Hungría y Polonia fueron los primeros países en solicitar formalmente su adhesión en marzo de 1994. En un plazo de dos años le siguieron: Bulgaria, la Rep. Checa, Estonia, Letonia, Lituania, Rumania, Eslovaquia y Eslovenia.

13 La Agenda evalúa el impacto de la expansión en los entonces quince Estados Miembros, llegando a la conclusión de que no habrá un incremento del presupuesto comunitario que supere $1,27 \%$ del PIB acumulado de dichos Estados miembros. Con todo, sugiere reformas financieras e institucionales para enfrentar dicha expansión 
lín de marzo de 1999. Luego de declarar que «la ampliación era una prioridad histórica» se reforzó el dispositivo de preadhesión prácticamente doblando la asistencia financiera de la Unión Europea a contar del año 2000 para alcanzar a 3,12 mil millones de euros anuales desde entonces hasta 2006, que se distribuyen en los programas de asistencia ya citados. Para algunos autores ${ }^{14}$ se trató de un verdadero «Plan Marshall» que la Comisión cifra en 75 mil millones de euros.

Establecido este dispositivo, había que proceder a determinar el ritmo con que se efectuarían las negociaciones de adhesión pertinentes. En la citada Agenda 2000, la Comisión se comprometió a proporcionar periódicamente al Consejo de Ministros una evaluación de la capacidad para ser miembros de los países candidatos. En esa ocasión, recomendó asimismo que en 1998 se iniciaran negociaciones con cinco países PECO: Estonia, Hungría, Polonia, Eslovenia, y República Checa, incluyendo a Chipre. Este ritmo, controvertido inicialmente, fue aceptado en una Conferencia Europea celebrada en Londres el 12 de marzo de 1998 y el 30 de marzo, las negociaciones comenzaron oficialmente dándose de esta manera «el puntapié inicial» al proceso de adhesión.

Esta lenta agenda de negociaciones diferenciadas sufrió, sin embargo, un tropiezo con la situación explosiva de Bosnia y la guerra de Kosovo. Pero

14 Quermonne, Jean Louis, op. cit, p.172. finalmente, en el Consejo Europeo de Helsinki, de diciembre de 1999, se acordó ampliar las negociaciones a Bulgaria, Letonia, Lituania, Rumania, Eslovaquia y Malta. Ellas se iniciaron al año siguiente.

Es muy comprensible que al cabo de prácticamente diez años los Estados candidatos estuvieran muy frustrados por el lento avance de sus solicitudes de adhesión no obstante las promesas recibidas en ese lapso. Se ha especulado que los países candidatos recibieron seguridades de que cinco años después de presentar su solicitud de adhesión serían miembros de la UE y concretamente, el ex presidente Jacques Chirac y el ex canciller Helmuth Kohl habían prometido a Polonia que sería miembro de la UE en el año $2000^{15}$.

Sabemos que estos buenos deseos demorarían todavía un poco más en concretarse. En efecto, bajo el permanente monitoreo de la Comisión Europea, los países candidatos debieron negociar su incorporación en forma paralela y a los distintos ritmos acordados (unos desde 1998 y otros desde 2000). En el curso del proceso, la Comisión procedió a verificar de manera sistemática cómo los Estados habían incorporado «l'acquis communautaire» (varios miles de páginas) antes mencionado. Estas complejas negociaciones abarcaron 31 capítu$\operatorname{los}^{16}$ de «l'acquis» en 372 sesiones.

15 «Europe's magnetic attraction», The Economist, 6 de enero del 2007.

16 Algunos de estos capítulos se refieren al mercado interior y la competencia, las 
Un elemento central fue que ningún candidato podía pedir una derogación de la reglas de la UE. Las negociaciones de adhesión también tenían en cuenta cuánto costaría a los candidatos incorporar plenamente dicho "acquis", y teniendo en cuenta este factor se les concedieron períodos de transición de seis meses a 12 años.

Otro elemento crucial en las negociaciones se relaciona con la ayuda financiera necesaria para la ampliación.

Concluidas estas etapas, en octubre de 2002 la Comisión Europea estuvo en condiciones de recomendar la incorporación de diez países a la UE, la que, como se señaló, se materializó en el Consejo Europeo de Copenhague del 13 de diciembre de ese año.

g) Futuras ampliaciones

La desintegración de la ex Yugoslavia ${ }^{17}$ que se tradujo en la guerra más

políticas comunitarias, la justicia y los asuntos internos, la política extranjera y la seguridad común.

17 La Comunidad estuvo desde un comienzo involucrada en obtener una solución pacífica a ese conflicto que se desató en junio de 1991 con la declaración de independencia de Eslovenia y Croacia. Posteriormente, efectuó vanos esfuerzos por obtener el cese del fuego, pero luego que Serbia invadiera a sus vecinos fue necesaria la intervención de las Naciones Unidas con la llegada de una fuerza de paz en marzo de 1992, apoyada por la OTAN. En agosto de 1995 se obtuvo en Dayton el cese de hostilidades después de los bombardeos aéreos sobre Serbia. La UE asumiría en- cruenta experimentada por Europa después de la Segunda Guerra Mundial, traería consigo la posibilidad de lo que se describió como "una nueva oleada en el proceso de ampliación», si bien después fue más acotada. Los Estados Miembros de la UE sentían especial responsabilidad hacia los pueblos involucrados en ese conflicto fratricida que no habían podido detener y que formaban parte del Continente europeo. A su vez, dichos pueblos estaban ansiosos de poder salir de la implacable lógica de la guerra y de la crisis, a la par que de romper con su pasado comunista. Para ello debían reconstruir su economía y sus instituciones, en lo cual la UE estaba llamada a cumplir un rol preponderante.

El ingreso de los Estados de la ex Yugoslavia a la familia europea fue preparado por varios acuerdos que visualizaban la perspectiva de una adhesión a mayor plazo: el Pacto de Estabilidad para la Europa del Sureste (aprobado en Colonia por el Consejo Europeo en 1999); la decisión de la Cumbre de Santa Maria da Feira del año 2000, que por primera vez precisa que « todos los Estados concernidos son candidatos potenciales a la adhesión a la Unión Europea», condición que reafirma la Declaración de Salónica (2003) al proclamar que « el futuro de los Balcanes se encuentra en la Unión Europea».

tonces un rol muy importante aportando ayuda para la reconstrucción de los territorios devastados. 
Paralelamente a esas declaraciones, a partir de 1999 la UE desarrolló un Proceso de Estabilización y de Asociación (PSA) en favor de los países de los Balcanes occidentales, que constituye el marco general del itinerario europeo de dichos países hasta su integración en la Unión. En ese contexto, se establecieron asociaciones europeas (ASA) con Albania, Bosnia y Herzegovina, la Antigua República Yugoslava de Macedonia, Montenegro y Serbia, incluido Kosovo, conforme a su definición por el Consejo de Seguridad de las Naciones Unidas.

Los acuerdos de asociación europea se proponen apoyar el proceso de estabilización y asociación ya descrito, así como el respeto de los criterios de adhesión (criterios de Copenhague). Además, proporcionan un marco coherente para las reformas que deben emprenderse así como un marco financiero para las mismas. La ayuda financiera que beneficia a los países de los Balcanes se concede a través del programa CARDS (2000-2006) que fue sustituido por el instrumento de ayuda de preadhesión (IAP) para el período 2007-2013.

Croacia y la Antigua República de Macedonia están en una situación especial ya que ambos fueron reconocidos como países candidatos en 2004 y 2005 respectivamente. Los Estados miembros de la UE iniciaron las negociaciones de adhesión con Croacia el 3 de octubre de 2005.

Este último debiera ser, por lo tanto, el 28 avo.miembro de la UE, pero su incorporación aún no ha podido materializar y por ahora no se avizora en un plazo cercano. Según la Comisión Europea $^{18}$, este país, conforme a los retos que se establecen para el 2007 , aún debe centrarse en la armonización con el acervo, la reforma judicial y de la administración pública, la lucha contra la corrupción y la reforma económica. Las buenas relaciones de vecindad y la cooperación regional siguen siendo esenciales y debe encontrarse soluciones a problemas bilaterales pendientes ${ }^{19}$. Los derechos de las minorías y la vuelta de los refugiados necesitarán una atención especial.

A su vez, en el caso de la Antigua República de Macedonia, la adhesión está más lejana, aunque se reconoce que haberse convertido en candidato constituye un reconocimiento al trabajo realizado. Sin embargo, debe intensificar el ritmo de sus reformas, en particular en los ámbitos policial y judicial, la lucha contra la corrupción y la aplicación íntegra del Acuerdo de Estabilización y Asociación.

De este modo, si se deja de lado por ahora el caso particular de Turquía, en

18 «Estrategia de ampliación 2006-2007: retos y capacidad de integración» <www. europa.eu/scadplus/ leg/es/lvb>.

19 Un hecho que retrasó considerablemente las negociaciones con Croacia, cuyo gobierno estaba convencido de que en la Cumbre de Copenhague de 2002 habría signos más concretos sobre su futura accesión, fue la demora en la entrega al Tribunal Penal Internacional de la ex Yugoslavia, para su juzgamiento, de un general croata (Gotovina) acusado de crímenes de guerra, condición que se cumplió a fines del 2005 cuando fue detenido en Tenerife. 
un futuro no muy lejano la UE acrecentaría su membresía a 30 Estados.

Pero la magnética atracción de Europa ha llevado a otros Estados a golpear la puerta de la UE para su futura admisión.

En vista de ello, la Comisión Europea, en un documento del 9 de noviembre de 2005 en que se diseñan estrategias para el futuro, manifestó que la actual propuesta de ampliación (Croacia, Turquía y los Balcanes occidentales) potencialmente bloqueaba la posibilidad de nuevas adhesiones de Armenia, Bielorrusia, Georgia, Moldavia y Ucrania. A su vez, Oli Rehn, Comisario Europeo encargado de las ampliaciones, sostuvo que la UE debía evitar «extenderse más allá nuestra capacidad y debiéramos más bien consolidar nuestra actual agenda de ampliación... lo que ya era un gran desafío».

\section{B. RETOS Y DESAFÍOS DE LA AMPLIACIÓN}

\section{a) Los ajustes institucionales}

A diferencia de las ampliaciones anteriores, que no necesitaron mayores ajustes (incluidos en los Tratados de Adhesión), la magnitud de la quinta obligó a la UE a hacer modificaciones significativas en su arquitectura institucional. Las reformas emprendidas para ajustar la UE a su nueva membresía fueron bastante controvertidas, como veremos en seguida.
Desde luego, los problemas que surgieron no tenían precedentes. Mientras que las anteriores ampliaciones agregaron a lo sumo tres nuevos miembros en cada oportunidad y no alteraron la relación de poder entre los pequeños y grandes Estados, la quinta ampliación involucró incorporar diez nuevos miembros, de los cuales nueve eran pequeños (con la sola excepción de Polonia). Ajustes meramente mecánicos no hubieran sido suficientes, ya que la sola ampliación de los tres más importantes órganos de la UE hubiera conducido a otorgar una influencia excesiva a los Estados más pequeños. Como lo indican John Peterson y Michael Shackleton ${ }^{20}$, en las negociaciones pertinentes «el clásico dilema federal entre la igualdad de los Estados y la igualdad de la población creció en intensidad. Como el régimen de la UE está basado en un complejo balance de representación estatal en los tres polos del triángulo institucional (léase Consejo, Comisión y Parlamento), cambios en una de las instituciones obligaba a hacer adaptaciones en las otras como también en el balance del poder de las instituciones».

Como se comprenderá, en este contexto surgirían fuertes diferencias estratégicas que dificultaron arribar a un compromiso, predominando la tesis de que era necesario consolidar la estructura institucional como condición previa a la ampliación.

20 The Institutions of the European Union (2006), Oxford, Oxford University Press, $2^{a}$ ed., p. 25. 


\section{El Tratado de Niza}

Como el Tratado de Ámsterdam de 1997 no pudo resolver la cuestión institucional ${ }^{21}$, se convocó a una nueva conferencia intergubernamental que aprobó el Tratado de Niza, de 22 de febrero de 2001, destinado a resolver los temas no resueltos en Ámsterdam (bautizados como los «flecos» de Ámsterdam), a saber: el tamaño de la Comisión, la ponderación del voto en el Consejo, la ampliación de la votación por mayoría cualificada en el Consejo, el Tribunal de Justicia y las cooperaciones reforzadas.

Después de dramáticos momentos y al cabo de cuatro días de intensas y disputadas negociaciones, se llegó a una solución de transacción sobre los temas controvertidos, que dejó a muchos descontentos, especialmente a Francia, país anfitrión ${ }^{22}$, quedando la impresión de que la obra no se había concluido.

21 En un Protocolo anexo preveía que con ocasión de la gran expansión futura los grandes Estados conservarían solo un Comisario en la Comisión a cambio de darles mejor ponderación al voto en el Consejo o bien mediante una doble mayoría. Estipulaba además que un año antes de que la Unión pasara a tener más de veinte Estados, una nueva Conferencia Intergubernamental debería revisar las disposiciones de los tratados sobre la composición y el funcionamiento de las instituciones.

22 «La Europa de ambiciones mitigadas", «La sombra de Niza que pesa sobre la presidencia francesa» eran algunos de los titulares de la prensa gala («Le Figaro») al término de esa Cumbre.
Tanto es así que como anexo al Tratado se aprobó una Declaración sobre el Futuro de la Unión, en que convocaba a una nueva Conferencia Intergubernamental para resolver una serie de problemas pendientes (4), que pasaron a ser los «flecos» de Niza.

Pero hay que convenir en que pese a sus deficiencias e imperfecciones, el Tratado de Niza abrió la puerta para la gran ampliación que se avecinaba, permitiendo que la UE pudiera seguir funcionando de manera más eficiente y representativa. Y sus disposiciones son las que rigen hasta hoy mientras no se apruebe un nuevo Tratado europeo.

Los principales acuerdos institucionales logrados en Niza fueron los siguientes:

a) Tamaño de la Comisión Europea: a contar del 1 de enero de 2005 habrá un Comisario por cada Estado miembro. Desde 1957 los Estados más poblados (Alemania, España, Francia Italia y el Reino Unido) tenían dos y los demás uno. Una ampliación sobre todo con otros Estados grandes (Polonia y Turquía, por ejemplo) -según se estimó- habría hecho casi inmanejable su labor. Se contemplaba además que cuando la UE se expandiera a 27 miembros el número de los miembros de la Comisión lo fijaría el Consejo procediendo por unanimidad y se fijaría sobre una base rotativa.

b) Ponderación del voto en el Consejo: siempre a partir de la misma fecha, se establece una nueva ponderación del voto en el Consejo para compensar a los Estados más grandes por la pérdida de 
un Comisario en la Comisión, estableciéndose un complejo dispositivo ${ }^{23}$.

c) Mayoría cualificada: para evitar una parálisis de la Unión con el ingreso de nuevos miembros y la aplicación del veto, se ampliaron a 29 las disposiciones del Tratado de la CE que pueden resolverse con esta mayoría.

d) Parlamento Europeo: se extiende su rol y se fija su número en un máximo de 732 eurodiputados (antes eran 626).

Al poco tiempo de la firma del Tratado de Niza y estando aún pendiente su ratificación, la Presidencia belga de la UE promovió la iniciativa no solo de resolver los problemas pendientes, sino de emprender la ambiciosa tarea de elaborar un nuevo tratado fundamental para la Unión Europea. Ello en el marco del creciente desinterés que se manifestaba en Europa por el proyecto europeo.

La Declaración de Laeken, de diciembre de 2001, diseñó el marco conceptual de esa iniciativa y en el Consejo Europeo respectivo se lanzó la convocatoria a una "Convención sobre el futuro de Europa». Esa Convención, ampliamente representativa (220 personas provenientes de los Parlamentos nacionales, los gobiernos, el Parlamento

23 Los cálculos reposan sobre tres parámetros: una ponderación del voto favorable a los grandes Estados; la exigencia del voto favorable de al menos 8 Estados; la verificación de que la decisión respectiva ha sido aprobada por Estados que representan el $62 \%$ de la población de la UE (disposición destinada a favorecer a Alemania). europeo y la Comisión Europea), tras poco más de un año y medio de trabajo concluyó su labor en julio del 2003, con la aprobación de un «Proyecto de Tratado por el que se instituye una Constitución para Europa».

Empero, el primer intento de aprobarlo a nivel gubernamental fracasó, lo que era ya preludio de lo que sucedería en el futuro. Desde marzo a diciembre de 2003 se celebraron diversas reuniones que no lograron desbloquear el impasse producido. Los puntos de discordia abarcan puntos sensibles sobre la composición de la Comisión, que inquieta a los pequeños países; la mayoría cualificada y la ponderación del voto en el Consejo, resistida por España y Polonia, que estaban más satisfechos con lo que habían obtenido en Niza.

Finalmente, los 25 lograron un difícil compromiso en la Cumbre de Bruselas de junio de 2004 y en su forma definitiva, el Tratado Constitucional fue firmado en Roma el 29 de octubre de 2004. Este, entre otras materias, modifica toda la estructura jurídica de la UE y contiene reformas importantes en el sistema institucional de la UE, que es el tema que mayormente nos interesa y que conviene analizar no obstante la suerte que correría el Tratado.

Como es ampliamente conocido, el Tratado Constitucional nunca entró en vigencia aunque fue ratificado por 18 Estados signatarios, declarándosele posteriormente «muerto y enterrado» por algunos medios de prensa e inclusive por algunos políticos, entre ellos el actual Presidente de Francia, Nicolas 
Sarkozy, durante su campaña presidencial. A esta no declarada defunción contribuyeron fundamentalmente los resultados adversos de los referendos de Francia y Holanda de mayo y junio de 2005, que provocaron un verdadero terremoto político en Europa, ahondando la crisis de euro-escepticismo que invadía el Continente. Entonces, la UE se declaró en estado de «reflexión» hasta que la nueva Presidencia alemana, que se iniciaba en enero de 2007, sacara a la entidad, con nuevas ideas, del estado de letargo que la consumía. Ello no ocurrió hasta junio del presente año.

\section{El Tratado Constitucional Europeo} (aspectos institucionales) $^{24}$

El análisis de estos aspectos no tiene un carácter histórico, ya que algunos de sus elementos están siendo recogidos en el nuevo tratado de reforma, que debe firmarse próximamente (Tratado de Lisboa). Veamos por ello las principales modificaciones institucionales que tienen incidencia directa con el tema de la ampliación:

- Tamaño de la Comisión Europea: se redujo el número de los Comisarios de uno por cada Estado Miembro (Tratado de Niza) a un número equivalente a los dos tercios del número de Estados miembros, con una rotación igual y

24 Un análisis detallado de este tema se encuentra en Piris, Jean Claude, (2006), El Tratado Constitucional para Europa: un análisis jurídico, Madrid-Barcelona, Editorial Marcial Pons. con independencia del tamaño o de la población de los Estados. Cada Estado miembro tendrá a un ciudadano suyo durante dos mandatos de cada cinco años (es decir, 10 años de cada 15). Ello se aplicaría a contar del año 2014.

- Mayoría cualificada en el Consejo: se establece un sistema llamado de «doble mayoría», concebido para reflejar la unión de Estados y la unión de ciudadanos. Para llegar a esta fórmula fue necesario un largo y áspero proceso previo de negociaciones que combinaba los factores demográficos y los intereses de los países más pequeños estableciéndose dos umbrales: al menos el 55\% del número de Estados miembros y al menos el $65 \%$ de la población de la Unión. Esta mayoría acumulativa para tomar decisiones se define «como un mínimo del $55 \%$ de los miembros del Consejo que incluya al menos a quince de ellos y represente a Estados miembros que reúnan como mínimo el $65 \%$ de la población de la Unión». Se añade que «una minoría de bloqueo está compuesta al menos por cuatro miembros del Consejo, a falta de lo cual la mayoría cualificada se considerará alcanzada ${ }^{25}$.

- Parlamento Europeo: se convino que el número de representantes no

25 Se prevé además que cuando el Consejo no actúe a propuesta de la Comisión o del Ministro de Asuntos Exteriores, la mayoría cualificada se definirá como un mínimo del $72 \%$ de los miembros del Consejo que representen a Estados miembros que reúnan como mínimo el $65 \%$ de la población de la Unión. 
puede exceder de 750 y que «la representación de los ciudadanos será decrecientemente proporcional con un mínimo de seis diputados por Estado miembro. No se asignará a ningún Estado miembro más de noventa y seis escaños». El umbral de seis asientos para los países más pequeños fue arduamente discutido pero se concedió este número como compensación a los Estados más grandes que vieron reducidos sus aspiraciones en el tamaño de la Comisión.

Como ya señalamos todas estas reformas han quedado teóricamente en suspenso y entretanto siguen rigiendo las disposiciones institucionales establecidas por el Tratado de Niza.

Hubo que esperar el Consejo Europeo de Bruselas, de 21 al 23 de junio del presente año, para que en el incierto derrotero europeo se abrieran nuevas perspectivas acerca de estas reformas.

En dicha Cumbre de líderes europeos, presidida por la Canciller de Alemania, Angela Merkel, después de arduas negociaciones, se llegó a una solución de compromiso mediante un mandato (de 16 páginas) relativo al marco de un nuevo Tratado simplificado que sustituya a la difunta Constitución. Este nuevo tratado de reforma (Tratado sobre el funcionamiento de la Unión) debía ser elaborado en el curso del presente año por una Conferencia Intergubernamental que sesionaría durante un periodo de tres meses y que se inauguró el 23 de julio pasado, ocasión en que la Presidencia portuguesa presentó un "proyecto de Tratado por el que se modifican el Tratado de la Unión Europea (léase Tratados de Maastricht, Ámsterdam y Niza) y el Tratado Constitutivo de la Unión Europea (Tratado de Roma)». Después de las negociaciones de redacción pertinentes y de los trabajos del Grupo de Expertos Jurídicos, el 5 de octubre, la Presidencia, por conducto de la Conferencia Intergubernamental, transmitió a los Estados miembros el proyecto final ${ }^{26}$, compuesto de 294 artículos más anexos (protocolos y declaraciones al Acta Final).

En el ámbito institucional, que es el que nos interesa mayormente analizar, el nuevo Proyecto de Tratado mantuvo una composición reducida de la Comisión ${ }^{27}$ Europea y la regla de la doble mayoría para adoptar las decisiones del Consejo. Pero cabe recordar que en Bruselas el compromiso propuesto por la Canciller Merkel estuvo a punto de naufragar. En esa oportunidad se logró mantener el

26 Este Proyecto de Tratado en su versión española se encuentra en <www.consilium.europa.eu/uedocs>.

27 Se establece que la Comisión nombrada entre la entrada en vigor de este nuevo Tratado y el 31 de octubre de 2014 estará compuesta por un nacional de cada Estado miembro incluido su Presidente y el Alto Representante de Asuntos Exteriores y Seguridad. A partir de esa fecha estará compuesta por un número correspondiente a los dos tercios del número de Estados miembros, incluyendo las personalidades nombradas, a menos que el Consejo Europeo decida por unanimidad modificar ese número. 
principio, pero a petición de Polonia ${ }^{28}$ su aplicación se postergó hasta el año $2014^{29}$.

El 18 de octubre recién pasado, los líderes de los 27, reunidos en el marco de la Conferencia Intergubernamental en Lisboa, concluyeron un histórico acuerdo transcurridos más de dos años desde los referendos negativos de Francia y Holanda, dando nacimiento al denominado nuevo Tratado de Lisboa, ya que debe ser firmado en la capital portuguesa el 13 de diciembre próximo.

El Primer Ministro portugués saludó este acuerdo como una gran «victoria

28 Polonia estuvo a punto de ser marginado del compromiso de Bruselas por insistir en una compleja fórmula que, utilizando la raíz cuadrada, le entregaba más votos en el Consejo, no obstante tener 38 millones de habitantes, mientras que Alemania, que la dobla en población, tenía una representación poco mayor.

29 Concretamente, por lo que se refiere a la controvertida cuestión de la «doble mayoría», un nuevo artículo $9 \mathrm{C}$, pto 4 , del Proyecto de Tratado mencionado dispone que: "A partir del 1 de noviembre de 2014, la mayoría cualificada se definirá como un mínimo del $55 \%$ de los miembros del Consejo que incluya al menos a quince de ellos y represente a Estados miembros que reúnan como mínimo el $65 \%$ de la población de la Unión.

La minoría de bloqueo deberá estar compuesta por al menos cuatro miembros del Consejo, a falta de lo cual se considerará alcanzada la mayoría cualificada» Otras disposiciones transitorias sobre la mayoría cualificada hasta el 31 de octubre de 2014 y entre el 1 de noviembre de ese año y el 31 de marzo de 2017 se establecerán en un Protocolo separado. para Europa» toda vez que ponía término a la parálisis institucional que afectaba a la UE, permitiéndole mirar el futuro con mayor optimismo. A su vez, el Presidente de la Comisión Europea, José Manuel Barroso, se mostró esperanzado de que en adelante «la UE será más fuerte para asumir su rol en el mundo y resolver los problemas económicos de sus habitantes».

Para sellar este acuerdo los líderes europeos, una vez más debieron realizar denodados esfuerzos para lograr una solución de compromiso que pudiera satisfacer las objeciones que presentaron Italia y Polonia.

El gobierno de Roma exigía una mayor representación en el Parlamento europeo al que, como vimos, se le había fijado un techo de 750 diputados. Para satisfacer esta solicitud italiana se acordó mantener el número, sin contabilizar al Presidente de dicho cuerpo legislativo $(750+1)$. De esta manera, el escaño que resta se atribuirá a Italia, que obtiene así 73 bancas al igual que el Reino Unido, y una menos que Francia (74).

Más compleja nuevamente resultó la exigencia polaca, que consistía en incluir en el cuerpo del Tratado el llamado "compromiso de Ionnina", de 1994, en virtud del cual el Consejo puede retrasar la adopción de una decisión por mayoría cualificada sin alcanzar el umbral de votos necesario para formar una minoría de bloqueo. En ese caso, el Consejo «hará cuando esté en su mano, para lograr dentro de un plazo razonable... para llegar a una solución 
satisfactoria» que permita adoptar una decisión con menos votos que los requeridos. Esta cláusula se incorporó finalmente en una Declaración anexa al Tratado, lo que facilitará su enmienda en el futuro ${ }^{30}$.

Una vez que el texto de este nuevo Tratado sea suscrito en Lisboa, como las nuevas elecciones del Parlamento europeo deben realizarse en junio de 2009, se espera que durante 2008 todos los Estados miembros lo hayan ratificado, de modo que entre en vigor el 1 de enero de 2009.

Por ahora, salvo Irlanda, todos los Estados miembros (entre ellos Francia), han declarado que sus Parlamentos lo ratificarán sin que sea necesario un referéndum, para evitar lo sucedido con el Tratado Constitucional. Sin embargo, ya en algunos países como el Reino Unido y Dinamarca han surgido importantes corrientes de opinión que exigen que sea sometido a la aprobación popular.

En resumen, con este nuevo andamiaje institucional, la UE ya se encuentra en condiciones de integrar a los nuevos miembros a contar de 2014 . Ahora solo cabe esperar que el nuevo Tratado de Lisboa entre en vigor en las fechas indicadas.

\section{b) Capacidad de absorción}

Un tema que ha estado siempre presente en los debates de cada etapa de la ampliación europea dice relación con la «capacidad de absorción» o de «asimilación» de la UE al ingreso de los nuevos miembros. Otros prefieren hablar de «integración» incluyendo en ella a los países candidatos.

Ya en el Consejo Europeo de 1992 de Copenhague se mencionó este concepto, sin dejar de mantener el impulso a la integración europea. Posteriormente, en 2005 la Comisión Europea, reiterando la importancia de la ampliación, señaló que el ritmo de ésta debe tener en cuenta esa capacidad de absorción. Los Consejos Europeos de junio y diciembre de 2006 nuevamente debatieron la cuestión estableciendo el primero que «en el futuro será importante asegurarse de que la Unión pueda funcionar política, financiera e institucionalmente a medida que se amplía». El segundo, que tenía el mandato de definir el concepto, se circunscribió a señalar en términos generales que «la Unión en la medida que se amplía, una exitosa integración requiere que las instituciones de la UE funcionen de manera eficiente y que las políticas de la UE se desarrollen ulteriormente y sean adecuadamente financiadas».

Aunque no se haya dado aún esa definición, según el gobierno francés ${ }^{31}$,

31 Declaraciones de la Ministra de Asuntos Europeos ante el Senado francés en marzo de 2006, poco antes del referéndum sobre el Tratado Constitucional. 
el concepto abarca tres dimensiones: la dimensión democrática y el respaldo de la opinión pública; la dimensión política y financiera y la dimensión institucional.

Mencionada ya la dimensión institucional y de paso la dimensión financiera, conviene detenerse a examinar lo que se ha calificado como el «déficit democrático» del proceso de ampliación, que inicialmente descuidó la opinión de los ciudadanos, por más que fuera aprobado por los gobiernos democráticos de los Estados miembros, siendo considerado más una obra de lo que se tildó la «élite o la burocracia de Bruselas». Los referendos negativos de Francia y Holanda a la Constitución europea fueron en buena medida producto del desconocimiento no solo del proyecto europeo en su conjunto sino también de las aprensiones que suscitaba la ampliación de la UE, no obstante que muy pocos desconocían la importancia que tenía para la reunificación europea ${ }^{32}$.

Las encuestas reflejaron que esa expansión provocaba algunas de las siguientes interrogantes: ¿la ampliación

32 Según el sondeo Eurobarómetro $N^{\circ}$ 64, realizado en octubre y noviembre de 2005 , sobre el respaldo a la ampliación en los 25 Estados miembros, el 49\% está a favor de futuras ampliaciones y el 39\% en contra, pero algunos grandes países europeos como Francia $(60 \%)$ y Alemania $(59 \%)$ son contrarios a ella. En un sondeo posterior de marzo y abril del 2006 se confirma esa tendencia con un $45 \%$ a favor y $42 \%$ en contra, lo que evidencia el alto nivel de desaprobación a las ampliaciones futuras. de 2004 se hizo con demasiada rapidez?; ¿fue preparada correctamente?; ¿se producirá pronto otra gran ampliación?; ¿es cierto que la ampliación impedirá continuar la profundización de la UE?; ¿no implica la llegada masiva de trabajadores a los viejos Estados miembros?; ¿no ha dado lugar a la relocalización de empresas?; ¿ha distorsionado el funcionamiento del mercado interno?; ¿no ha resultado demasiado cara?; iha ocasionado un aumento de la inmigración ilegal y de la delincuencia organizada?; ¿supone la ampliación un riesgo para la seguridad de los alimentos y el medio ambiente?; ¿no deberíamos fijar las fronteras de la UE de una vez por todas? Otras aprensiones manifestadas se referían concretamente a Turquía y a la inestabilidad en los Balcanes occidentales.

Para rectificar este estado de cosas, la Comisión Europea se ha preocupado de fijar desde su estrategia de ampliación de 2005, entre otros principios, el siguiente: «comunicación al público para que la ampliación sea un éxito, es decir, garantizar el apoyo de los ciudadanos y la legitimidad democrática del proceso». Con este propósito, la Comisión publica periódicamente documentos ${ }^{33}$ que explican el proceso de ampliación y lleva a cabo una activa campaña de relaciones públicas en torno al tema. También ha elaborado comunicaciones al Parlamento Euro-

33 Un interesante documento que responde a las interrogantes antes mencionadas se titula «Mitos y realidades de la Ampliación» ( http://ec.europa/cgi-bin/etal.pl) 
peo y al Consejo sobre las estrategias de ampliación, la última de 8 de noviembre de $2006^{34}$. Allí se recoge esta inquietud manifestando que la legitimidad democrática implica que Europa debe escuchar las expectativas de sus ciudadanos obteniendo su apoyo para sus políticas, incluyendo la ampliación. Reconoce que las ampliaciones anteriores "generalmente han recibido el respaldo de la opinión pública, pero también han originado dudas y aprensiones». En ese aspecto concluye "que los ciudadanos deben estar mejor preparados para las ampliaciones futuras».

En aras de esta misma legitimidad democrática, en Francia se aprobó el 1 de marzo 2005 una Ley Constitucional que obliga al Ejecutivo a someter a referéndum cualquier adhesión futura que no sea la de Croacia.

Con el tiempo se podrá medir si estas diversas medidas sirven para paliar la «fatiga hacia la ampliación» que ha acompañado recientemente este proceso en los antiguos miembros de la UE, pero es evidente que en el futuro la expansión europea será más compleja y escalonada ${ }^{35}$.

34 «Estrategia de ampliación 2006-2007: retos y capacidad de integración» (en inglés «Enlargement Strategy and Main Challenges 2006-2007»), ambas versiones citadas.

35 En el Consejo Europeo de Bruselas de 14 y 15 de 2006 se fijó una estrategia de ampliación que se ciñe a lo anterior, disponiéndose además que la UE evitará fijar fechas de adhesión (como ocurrió con

\section{c) La adhesión de Turquía a la} Unión Europea ${ }^{36}$

Sin lugar a dudas, el ingreso de Turquía a la UE es uno de los temas más conflictivos que cruza todo el espectro del proyecto europeo y tiene profundas consecuencias en las relaciones estratégicas de Europa con el mundo islámico e incluso con Estados Unidos, país que por estas razones presiona fuertemente por dicho ingreso. La cuestión es tan controvertida que en las últimas elecciones presidenciales francesas se convirtió en uno de los temas más conflictivos de política exterior entre los dos principales contendores (Ségolène Royal y Nicolas Sarkozy) y algunos sostienen que es «un factor clave sobre el rol de Europa en el mundo» ${ }^{37}$.

Durante 2007, la UE ha logrado de alguna manera congelar este desafío para concentrarse más bien en las reformas institucionales, pero en el futuro, resueltas estas últimas, más bien tarde que temprano, deberá resolver el dilema de si Turquía tiene cabida en el contexto europeo en calidad de miembro y no solo de «socio» como lo preconizaba recientemente el Presidente de Francia. En todo caso, fuentes europeas han indicado que un eventual ingreso de

Bulgaria y Rumania) hasta que se hayan completado las negociaciones.

36 Para un análisis más detallado de las relaciones entre la UE y Turquía, ver informe respectivo preparado por EuroActiv (www. euroactiv.com/en/enlargement/eu-turkeyrelations).

37 International Herald Tribune, 15 de septiembre de 2006. 
Turquía no se producirá antes de diez o quince años y en todo caso después de 2014, fecha en que se aplicarán los arreglos institucionales y financieros convenidos en el proceso de reformas de la UE con la participación de los nuevos miembros.

Pero antes de plantear las interrogantes que suscita este tema, recordemos de manera somera los diversos hitos que han jalonado el proceso de adhesión de Turquía. Las relaciones en este país y la UE datan de $1963^{38}$, cuando se suscribió un Acuerdo de Asociación (el Acuerdo de Ankara). En 1987, Turquía presentó su solicitud de adhesión, pero la opinión de la Comisión (1989) fue que no sería útil entablar negociaciones de adhesión de inmediato, pero que debían profundizarse las relaciones. En 1995 se estableció una Unión Aduanera y en 1997 el Consejo Europeo de Luxemburgo reconoció la capacidad de Turquía de ser elegido miembro. En 1999, el Consejo Europeo de Helsinki le otorgó el «status» de país candidato. En el Consejo Europeo de Copenhague de 2002 que, como se dijo, resolvió la quinta ampliación, las expectativas de Turquía de que se le fijara una fecha para iniciar las negociaciones no cristalizaron, ya que se limitó a encomendar al Consejo Europeo de diciembre de 2004 que determinará si el país cumplía con los requisitos de adhesión (los criterios de Copenhague), para iniciar

38 Antes, en 1959, había solicitado la condición de miembro asociado de la Comunidad. negociaciones «sin demora». De paso, en dicho Consejo se aceptó la admisión de Chipre dividido, ya que antes habían fracasado los esfuerzos por reunificar la isla en un referéndum auspiciado por las Naciones Unidas ${ }^{39}$. Finalmente, en diciembre de 2004, el Consejo Europeo concluyó que Turquía cumplía con los criterios políticos para iniciar las negociaciones de adhesión el 3 de octubre de 2005, y se dejó constancia de los evidentes progresos alcanzados.

A partir de entonces, se abrió un «riguroso» marco de negociaciones que se realizaron en una Conferencia Intergubernamental sin fecha de término ( «open-ended») que abarca 35 capítulos, esto es, más que en las anteriores negociaciones y que debe concluir con una «decisión unánime». La Comisión y el Parlamento emiten informes periódicos sobre los avances logrados.

Los resultados obtenidos hasta ahora en estas negociaciones demuestran que el Gobierno turco ha avanzado en algunas reformas internas, lo que permitió abrir los capítulos de negociación sobre ciencia e investigación (ya cerrados) y asuntos industriales, pero a fines de 2006 la Comisión Europea divulgó un informe crítico en que pide a Turquía acelerar el ritmo de las reformas, mencionando en particular sobre libertad de expresión, libertad de culto, derechos de la mujer, derechos

39 Después de la anexión militar de la zona norte por tropas turcas en 1974 y de la declaración de independencia de dicha zona, proclamada como República en 1983, la isla se encuentra dividida. 
de las minorías y sindicales, el refuerzo del control democrático civil sobre los militares y los derechos de la población kurda.

Pero sin duda el aspecto más contencioso dice relación con la cuestión chipriota, que sigue siendo uno de los principales obstáculos para avanzar más resueltamente en las negociaciones. El mayor punto de discordia es la negativa turca de reconocer la parte griega de Chipre (la UE insiste en que Turquía debe normalizar sus relaciones con todos sus miembros) y autorizar la entrada en sus puertos a los buques y aviones procedentes de este miembro de la UE. Este virtual bloqueo turco viola el llamado protocolo adicional al Tratado de Ankara de 2005, acuerdo aduanero conforme al cual Turquía debe permitir el libre tráfico de personas y mercancías a los países de la UE.

Como resultado de este serio impasse, en la Cumbre de Bruselas de diciembre de 2006, los 27 miembros de la UE tomaron la drástica decisión de suspender 8 de los 35 capítulos de negociación con Turquía, entre los cuales se cuenta el de tránsito aduanero. En todo caso, como señal de que las negociaciones prosiguen, la UE accedió a abrir este año las discusiones sobre dos nuevos capítulos (estadísticas y control financiero, así como uno de los más importantes sobre política económica y financiera). Pero aquí se produjo un hecho anunciado. El gobierno francés se opuso a que se discutiera este último capítulo, por considerar que era una materia muy sensible ya que significaba un paso en la dirección de una futura incorporación turca a la zona del euro, circunstancia que tendría una resonancia política y simbólica muy importante. Esta obstrucción fue recibida con gran malestar en Ankara.

La reacción francesa no debe haber motivado mucha sorpresa ya que durante la reciente campaña presidencial francesa y una vez elegido en mayo pasado, el presidente Sarkozy ha manifestado reiteradamente que es contrario a la adhesión de Turquía a la UE porque geográficamente no es un país europeo ${ }^{40}$ y que «no tiene lugar en Europa por una razón simple: porque está en Asia Menor». Efectivamente más del $90 \%$ de su territorio se encuentra en Asia.

Las razones explicitadas tan claramente por Francia entran de lleno en el corazón de los motivos por las cuales también otros países europeos (Austria en particular) se oponen a su incorporación (solo el Reino Unido y Suecia aparecen como partidarios entusiastas). El tema de Chipre, según algunos observadores, no es más que un argumento secundario pero útil para algunos Estados miembros también contrarios.

Además de las razones geográficas indicadas, otras razones demográficas, políticas y culturales se esbozan para justificar ese rechazo.

40 Una de las principales razones del rechazo francés es que el triunfo del «no» en el referéndum sobre el Tratado Constitucional obedeció al temor de que Turquía ingresara a la UE en las encuestas $(52 \%$ de los franceses se manifectó en este sentido). 
Desde el punto de vista demográfico, se anota que si Turquía ingresa a la UE será en breve el país más poblado, lo que conlleva mayor participación en sus decisiones. Actualmente, con sus $71 \mathrm{mi}^{-}$ llones, es el segundo más poblado después de Alemania (83 millones), pero se prevé que dentro de 20 años debido a su mayor crecimiento demográfico ese orden se verá trastocado.

Asimismo, se esgrime, como la ha hecho Francia, que debieran establecerse los límites geográficos de Europa. Esta es una vieja aspiración ya que efectivamente al establecer la CE el Tratado de Roma no definió lo que debía entenderse por "país europeo", ni sus fronteras. Solo una vez, en el caso de Marruecos, se estimó que no era un país del continente europeo. Pero ¿puede aplicarse el mismo parámetro a Turquía, que está fuertemente anclada a Europa y que es miembro de la OTAN, de la OCDE y está asociada a Unión de Europa Occidental, siendo además Estambul un centro principal de la historia y la cultura europeas?

Otro argumento que se ha invocado es que los valores culturales y religiosos distinguen a Turquía de los demás socios europeos, pero es rechazado sosteniéndose que las creencias religiosas no son un requisito para la admisión y que, por el contrario, la UE se ha construido en torno a ciertos valores esenciales como son la tolerancia religiosa y el respeto por la diversidad. Este argumento se apoya en el hecho de que en la UE viven 12 millones de musulmanes y que Turquía es un Estado laico, ciertamente con una amplia mayoría musulmana, pero que pertenece a las corrientes moderadas del Islam.

Como puede apreciarse, esta es una cuestión de enorme complejidad, a lo cual se une la circunstancia de que a pesar de ciertos retrocesos, el actual Gobierno turco ha conducido al país hacia una mayor estabilidad económica y de respeto a las reglas democráticas y los derechos humanos, factores que deben perfeccionarse y que están bajo constante escrutinio por parte de la UE. Por otro lado, la presencia estratégica y geopolítica de Turquía en el inestable Medio Oriente e Irak es de vital importancia para la UE y el Occidente. A ello se suman que su presencia aumentaría el tamaño del mercado europeo en varios millones de habitantes y que el país juega un rol vital en el mercado de la energía, ya que es un corredor muy importante para el tránsito del petróleo proveniente de las naciones vecinas.

El gran dilema que subsiste es cómo la UE podrá salir de este atolladero y cumplir la promesa que asumió al aceptar a Turquía como país candidato a la adhesión y no como país con una «asociación privilegiada», como se le ha ofrecido y que Ankara rechaza con energía.

Por ahora, y quizá por mucho tiempo, el reto de cómo resolver este incordio recae en los líderes europeos. Lo que sí está claro es que a menos que haya una nueva generación de líderes y un vuelco importante en la opinión publica europea, el acceso de Turquía a la UE parece muy improbable. 


\section{Conclusiones}

Como lo ha destacado el balance que hizo la Unión Europea en $2006^{41}$ al celebrar el segundo aniversario de la quinta ampliación, es evidente que esta expansión ha sido un notable éxito. Las fronteras de la Unión Euopea se han expandido, se han incrementado su población y su producto nacional y se ha ampliado su diversidad cultural, histórica y económica. Paz, democracia y prosperidad prevalecen hoy en toda Europa. La ampliación no creó problemas de absorción para la Unión Europea, ni estimuló un éxodo masivo de mano de obra que afectara a los antiguos países de Europa provocando trastornos en sus mercados laborales, como se temía. Los nuevos países adoptaron un proceso de modernización de su cultura política y administrativa, pese a las turbulencias políticas internas propias de todas las democracias nacientes.

Desde un punto de vista económico, la ampliación ha acarreado beneficios no solo a los nuevos Estados sino también a los15 miembros antiguos. Los primeros están rápidamente acortando la brecha que los separa de los segundos. Estos, a su vez, se han beneficiado con las nuevas oportunidades de comercio e inversiones. La extensión del mercado interno y la rápida integración de los nuevos miembros a la economía

41 «Enlargement, two years after-an economic evaluation» «http://ec.europa.eu/ economy_finance/publications/occasionalpapers/2006». de la Unión Europea permitieron que sus empresas relocalizaran sus actividades para incrementar sus márgenes de utilidad. En términos generales, la ampliación «ha sido beneficiosa para el conjunto de la economía de la UE y le permite enfrentar mejor los desafíos de la globalización» señala dicho balance.

En fin, la ampliación ha incrementado la influencia y el peso de la UE en el escenario político y económico mundial. Ello se hará más evidente una vez que se deje atrás la crisis institucional, como ya se avizora.

No podemos sino compartir estas palabras de autocomplacencia, que se acompañan de abundantes evidencias.

Sin restar méritos a lo anterior, cabe sin embargo reconocer que la Unión Europea debe redoblar sus esfuerzos por asegurar una mayor transparencia del proceso, introduciendo una fase de reflexión y de pausa antes de proseguir la expansión (tal vez una definición de los límites de Europa facilitaría esta labor). Claramente sus pueblos no estarían preparados para una próxima ampliación y se precisa que el tiempo los haga superar su actual suspicacia y apatía.

\section{Bibliografía}

Maximiliano, Bernad, Sergio Salinas y Carmen Tirado (2003), Instituciones y Derecho de la Unión Europea, Zaragoza, Realizaciones, Informes y Ediciones Europa.

Cartou, Louis, Jean-Louis Clergerie, Annie Gruber y Patrick Ramboud (2006), L'Union européene, París, Dalloz. ( $6^{\mathrm{a}} \mathrm{ed}$.) 
Jaime Lagos Erazo • La ampliación de la Unión Europea

Gautron, Jean Claude ( 2006), Droit européen, París, Dalloz. (12 ${ }^{\mathrm{a}}$ ed.)

Dick, Leonard (1994), Guide to the European Union, The Economist, $6^{\mathrm{a}}$ ed.

Martínez Estay, José Ignacio (2007), Introducción al Derecho y a las Instituciones de la Unión Europea, Santiago. Editorial Jurídica de Chile.

Quermonne, Jean-Louis (2004), El Sistema Político de la Unión Europea, Santiago, Editorial Jurídica de Chile.
Peterson, John y Michael Shackleton(2006), The Institutions of the European Union, Oxford, Oxford University Press. (2a. ed.).

Piris, Jean Claude (2006), El Tratado Constitucional para Europa: Un Análisis Jurídico, Madrid, Barcelona, Marcial Pons Ediciones.

Unión Europea, portal de la Unión Europea «www.europa.eu/». 